\title{
Improving Radiation Awareness and Feeling of Personal Security of Non-Radiological Medical Staff by Implementing a Traffic Light System in Computed Tomography
}

\author{
Verbesserung des Strahlenbewusstseins sowie des Gefühls der persönlichen \\ Sicherheit von nicht-radiologischem medizinischem Personal durch Einführung \\ eines „Ampelsystems“ in der Computer-Tomografie
}

Authors

Affiliations

\author{
C. Heilmaier ${ }^{1}$, A. Mayor ${ }^{1}$, N. Zuber ${ }^{1}$, P. Fodor ${ }^{2}$, D. Weishaupt ${ }^{1}$
}

Department of Radiology and Nuclear Medicine, Stadtspital Triemli, Zurich, Switzerland

Department of Anesthesiology and Intensive Care Medicine, Stadtspital Triemli, Zurich, Switzerland

\author{
Key words \\ - CT \\ - radiation safety \\ - QA/QC
}

received 29.9.2015

accepted 16.11.2015

Bibliography

DOI http://dx.doi.org/

10.1055/s-0041-110450

Published online: 27.1.2016

Fortschr Röntgenstr 2016; 188:

280-287 @ Georg Thieme

Verlag KG Stuttgart - New York .

ISSN 1438-9029

\section{Correspondence}

\section{Christina Heilmaier}

Department of Radiology and Nuclear Medicine, Stadtspital Triemli

Birmensdorferstrasse 497

8063 Zurich

Switzerland

Tel.: ++ 41/44/4661452

Fax: ++41/44/4663426

christina.heilmaier@triemli.

zuerich.ch

\section{Zusammenfassung}

$\nabla$

Ziel: Oftmals muss nicht-radiologisches medizinisches Personal während einer Computer-Tomografie (CT) Untersuchung im Raum bleiben, um Patienten in kritischem Zustand zu überwachen. Auch wenn sie Schutzkleidung tragen, beeinflusst ihre Position innerhalb des Raumes ihre Strahlenbelastung. Das Ziel der vorliegenden Studie war es, zu überprüfen, ob ein „Ampelsystem“, das Bereiche mit unterschiedlicher Strahlenexposition anzeigt, das Strahlenbewusstsein sowie das Gefühl der persönlichen Sicherheit von nicht-radiologischem medizinischen Personal beeinflusst.

Material und Methoden: Zunächst wurden Phantommessungen durchgeführt, um Bereiche mit unterschiedlicher Strahlenbelastung zu definieren. Diese Bereiche wurden mit Aufklebern versehen, die entsprechend einem „Ampelsystem“ angeordnet wurden: grün=geringste, orange $=$ mittlere und rot $=$ höchste Strahlenexposition. Das System wurde von nicht-radiologischem medizinischen Personal mit unterschiedlicher Berufserfahrung mittels eines standardisierten Fragebogens evaluiert. Die statistische Auswertung erfolge mit Kruskal-Wallis und Spearman's Korrelationstests.

Ergebnisse: Insgesamt haben 56 Personen (30 Ärzte, 26 Pflegepersonal) an dieser prospektiven Studie teilgenommen. Das „Ampelsystem“ wurde insgesamt sehr geschätzt und fast alle Befragten haben sich bemüht, während der Untersuchung in den grünen Aufklebern zu stehen. Das Strahlenbewusstsein sowie das Gefühl der persönlichen Sicherheit sind durch das „Ampelsystem“ deutlich gesteigert worden, vor allem auch bei Berufsanfängern mit weniger als 5 Jahren Berufserfahrung $(p<0,05)$. Die Mehrheit der Befragten gab an, dass die Position der grünen Aufkleber gut mit einer adäquaten Patientenversorgung vereinbar ist. Kenntnisse im Strahlenschutz waren bei allen Befragten durchweg gering, insbesondere bei Berufsanfängern $(p<0,05)$.

\section{Abstract \\ $\nabla$}

Purpose: Non-radiological medical professionals often need to remain in the scanning room during computed tomography (CT) examinations to supervise patients in critical condition. Independent of protective devices, their position significantly influences the radiation dose they receive. The purpose of this study was to assess if a traffic light system indicating areas of different radiation exposure improves non-radiological medical staff's radiation awareness and feeling of personal security.

Material and Methods: Phantom measurements were performed to define areas of different dose rates and colored stickers were applied on the floor according to a traffic light system: green= lowest, orange $=$ intermediate, and red $=$ highest possible radiation exposure. Non-radiological medical professionals with different years of working experience evaluated the system using a structured questionnaire. Kruskal-Wallis and Spearman's correlation test were applied for statistical analysis.

Results: Fifty-six subjects (30 physicians, 26 nursing staff) took part in this prospective study. Overall rating of the system was very good, and almost all professionals tried to stand in the green stickers during the scan. The system significantly increased radiation awareness and feeling of personal protection particularly in staff with $\leq 5$ years of working experience $(p<0.05)$. The majority of non-radiological medical professionals stated that staying in the green stickers and patient care would be compatible. Knowledge of radiation protection was poor in all groups, especially among entry-level employees $(p<0.05)$.

Conclusion: A traffic light system in the CT scanning room indicating areas with lowest, in-termediate, and highest possible radiation exposure is much appreciated. It increases radiation awareness, improves the sense of personal radiation 
Schlussfolgerung: Ein „Ampelsystem“ im CT-Untersuchungsraum, das Bereiche mit geringster, mittlerer und höchster Strahlenexposition anzeigt, wird sehr geschätzt. Es erhöht das Strahlenbewusstsein und verbessert das Gefühl der persönlichen Sicherheit und könnte die Bemühungen zur Verringerung der beruflich bedingten Strahlenbelastung unterstützen, auch wenn nach wie vor der beste Strahlenschutz ist, sich während des Scans ausserhalb des CT-Untersuchungsraums aufzuhalten.

Kernaussagen:

- Ein „Ampelsystem“, das Bereiche mit unterschiedlicher Strahlenbelastung innerhalb des Computer-Tomografie-Untersuchungsraums anzeigt, wird von nicht-radiologischem medizinischen Personal sehr geschätzt.

- Das „Ampelsystem“ steigert das Strahlenbewusstsein sowie das Gefühl der persönlichen Sicherheit von nicht-radiologischem medizinischen Personal.

- Kenntnisse im Strahlenschutz waren insgesamt sehr gering, wobei dies vor allem bei Berufsanfängern sehr deutlich war. protection, and may support endeavors to lower occupational radiation exposure, although the best radiation protection always is to re-main outside the $\mathrm{CT}$ room during the scan.

Key Points:

- A traffic light system indicating areas with different radiation exposure within the computed tomography scanner room is much appreciated by non-radiological medical staff.

- The traffic light system increases non-radiological medical staff's radiation awareness and feeling of personal protection.

- Knowledge on radiation protection was poor in non-radiological medical staff, espe-cially in those with few working experience.

Citation Format:

- Heilmaier C, Mayor A, Zuber N et al. Improving Radiation Awareness and Feeling of Personal Security of Non-Radiological Medical Staff by Implementing a Traffic Light System in Computed Tomography. Fortschr Röntgenstr 2016; 188: 280-287

\section{Introduction}

$\nabla$

Considerable technical advances and greater availability of modalities have led to a marked increase of medical imaging with the majority relying on ionizing radiation [1]. In particular the number of computed tomography (CT) scans performed significantly grew, currently accounting for more than half of the collective radiation dose received by patients [2,3]. Nowadays CT constitutes an integral part of the diagnostic curriculum of most patients, including emergency and intensive care patients [4]. In particular, when imaging intensive care patients non-radiological medical staff often needs to remain in the CT room throughout the scan to keep patients in critical condition under surveillance [5]. As a consequence, non-radiological medical professionals are repeatedly exposed to ionizing radiation and therefore require appropriate protective tools and equipment [6, 7]. Based on national and international recommendations and regulations, these protective devices at least consist of an apron (or vest/skirt configuration) and a thyroid collar [6 - 9]. However, despite these safety precautions, some body parts are left vulnerable to radiation exposure [10] with scatter from the patient being the greatest source of radiation exposure [6, 7]. For this reason it is important that non-radiological medical staff stand in a low-scatter area and as far away from the X-ray beam as possible according to the inverse square law $[6,7]$. To follow these recommendations adequately, all medical professionals should receive appropriate education and training in radiation safety [7, $11-13]$.

Nonetheless, often a lack of radiation awareness and ignorance of radiation protection is apparent particularly in non-radiological medical professionals, which is frequently being accompanied by a feeling of personal endangerment due to radiation exposure. To overcome this uncertainty and lower occupational radiation exposure of non-radiological medical staff in our hospital, we performed dose measurements at several points close to our emergency CT scanner in order to define positions within the room with different exposure for medical professionals. To tag the different areas, we placed colored stickers on the floor according to a traffic light system with a green sticker indicating lowest and a red sticker implying highest possible dose rate. We informed our non-radiological medical staff about the rationale of the system and asked them to judge the stickers to learn about the advantages and disadvantages of our traffic light system.
The purpose of our study was to evaluate whether a traffic light system indicating areas of different radiation exposure raised radiation awareness of non-radiological medical professionals who need to remain in the CT room during the scan. Moreover, it was assessed if the system achieved an improvement of the staff's feeling of personal safety.

\section{Material and Methods \\ $\nabla$}

The study was conducted at one of our computed tomography (CT) scanners (LightSpeed VCT, GE Healthcare Systems, Milwaukee, WI, USA), which is located close to the emergency room and is preferentially used for imaging of patients from the emergency room and from the intensive care unit.

Before we applied the colored stickers, our medical physicists performed dose measurements to identify radiation exposure at different locations close to the CT gantry. Measurements were accomplished with a CT torso dose phantom, a X-ray multimeter (Barracuda, Version 1.3.2, RTI Electronics, Moelndal, Sweden) and a dose detector (R100B, RTI Electronics, Moelndal, Sweden) with an active detector area of $10 \times 10 \mathrm{~mm}$. Devices were calibrated at regular intervals. The protocol applied was a CT scan of the chest acquired with a tube voltage of $120 \mathrm{kV}$ and a tube current-exposure time product of $175 \mathrm{mAs}$. Measurements were performed at 13 different points within the CT scanner room. The points with the expected highest and lowest dose rate were chosen as points of reference to systematically cover the scanner room, and adequately reflect different dose rate within the scanner room. Each point was measured three times and average radiation exposure was calculated thereafter.

After the measurements colored stickers with a diameter of $30 \mathrm{~cm}$ were mounted on the floor according to a traffic light system, in which green implied lowest and red highest possible radiation exposure (orange $=$ intermediate dose rate; median of dose rate measurements $\bullet$ Fig. 1).

\section{Non-radiological medical staff and questionnaire}

Upon tagging the colored stickers to the floor the traffic light system was introduced in an interdisciplinary meeting to all non-radiological medical professionals (physicians and nursing staff), who potentially might accompany patients undergoing CT exam- 


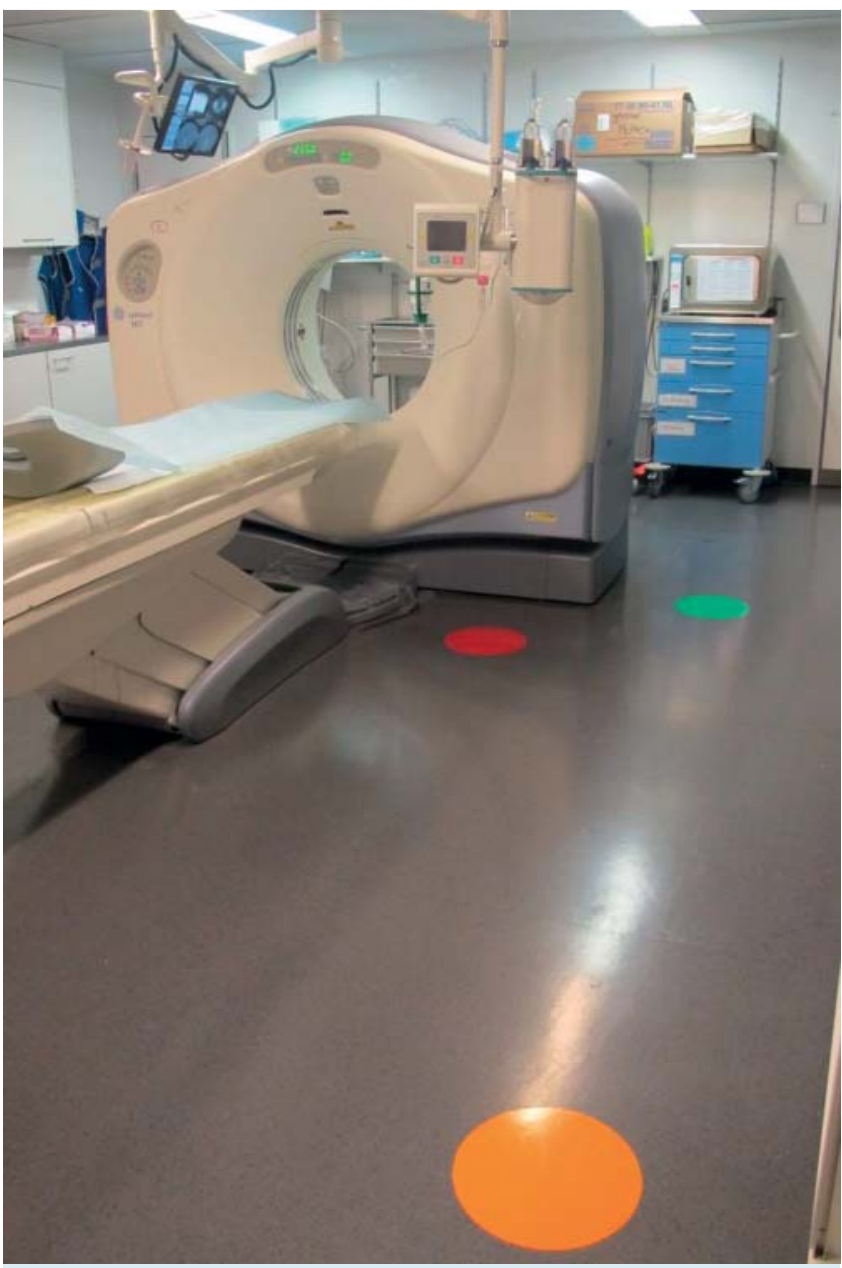

Fig. 1 A traffic light system was implemented in the CT scanning room to increase radiation awareness of non-radiological medical professionals and to improve their feeling of personal safety. The green sticker indicated lowest, the orange intermediate, and the red sticker highest possible radiation exposure of non-radiological medical staff, which was required to stay in the scanning room throughout the examination.

Abb.1 Um das Strahlenbewusstsein und das Gefühl der persönlichen Sicherheit von nicht-radiologischem medizinischen Personal zu erhöhen, wurde ein „Ampelsystem“ im CT-Untersuchungsraum eingeführt. Hierbei zeigten grüne Aufkleber die geringste, orange die mittlere und rot die höchste Strahlenbelastung von nicht-radiologischem medizinischen Personal an, das während der Untersuchung im Raum bei den Patienten bleiben musste.

inations. Moreover, emails explaining the rationale of the colored stickers were sent to transmit information to the non-radiological medical staff not present at the meeting. In addition, posters were attached to the main doors inside the scanning room as additional reminders of the traffic light system.

To guarantee radiation protection irrespective of the traffic light system, medical staff was obliged to wear a leaded apron and a thyroid collar in the scanning room throughout the examination. The investigation period lasted from January $1^{\text {st }}$, to March $31^{\text {st }}$, 2015 (= 90 days), and all non-radiological medical staff was requested to judge the traffic light system based on a standardized questionnaire, assessing practicability and utility of the system as well as radiation protection knowledge. Questions were as follows:
- No. 1: The colored stickers are useful.

- No.2: The green stickers are not compatible with patient care.

- No.3: I try to stand within the green stickers during the scan.

No.4: I feel safer with the stickers.

- No. 5: I already knew before where my best position was.

At this, a 5-point Likert scale was used with the following codification: 1 = I completely disagree, 2 = I partly disagree, 3 = neutral, $4=$ I partly agree, and $5=$ I completely agree. It was ensured that non-radiological medical professionals were only asked to evaluate the colored stickers after their first encounter with the traffic light system. If possible, the questionnaire was filled in directly after the scan; if it was not feasible, the non-radiological medical professionals answered the questions within 24 hours. In addition to the questions, basic demographic data was noted (gender, medical specialty, years of working experience), and the non-radiological medical staff's main motivation to stay in the scanning room was assessed.

Our local ethics committee approved this prospective study as part of the hospital's quality management system and informed consent was waived from all participants.

\section{Statistical Analysis}

A radiologist with 10 years of experience in CT and with special interest in radiation protection conducted data analysis. Data was manually transferred to Microsoft Excel 2013 (Redmond, WA, USA) and statistical evaluations were accomplished using SPSS, version 22 (IBM; Amonk, NY, USA). Analysis was done for all medical professionals together, separately for physicians and nursing staff as well as based on the years of working experience (4 groups: $1-2$ years, $3-5$ years, $6-10$ years, and >10 years, respectively).

To look for statistical comparisons between the groups the Kruskal-Wallis test was performed. Moreover, Spearman's correlation test was applied to find out whether years of working experience correlated with rating. For both, a p-value $<0.05$ was deemed to represent statistical significance.

\section{Results \\ $\nabla$}

\section{Phantom Measurements}

Based on the medical physicists' measurements, highest radiation exposure (20 micro-Gray per second; $\mu \mathrm{Gy} / \mathrm{s}$ ) was detected in the corner between the computed tomography (CT) bed and the scanner gantry as well as on the other side of the gantry close to the X-ray beam $(14.1 \mu \mathrm{Gy} / \mathrm{s})$; these areas were marked with red stickers. Lowest possible radiation exposure was evidenced at the lateral side of the gantry $(0.2 \mu \mathrm{Gy} / \mathrm{s})$, where green stickers were attached. Orange stickers, indicating intermediate radiation exposure $(1.9 \mu \mathrm{Gy} / \mathrm{s})$, were mounted on the floor with their center lying $1.35 \mathrm{~m}$ away from the CT bed and $1.75 \mathrm{~m}$ distant from the gantry in the direction of the foot end of the bed.

\section{Questionnaire}

A total of 56 non-radiological medical professionals answered the questionnaire after they had stayed in the CT scanning room during the examination. The 56 CT scans were performed of the head $(n=23)$, of head, thorax, and abdomen $(n=15)$, of thorax and abdomen $(n=12)$, or of the abdomen alone $(n=6)$.

The study group of the non-radiological medical professionals consisted of 33 women and 23 men with a mean working experience of 7.5 years (range, 1 to 21 years; $1-2$ years, $n=13 ; 3-5$ years, 
$\mathrm{n}=14 ; 6-10$ years, $\mathrm{n}=13 ;>10$ years, $\mathrm{n}=16$ ). Thirty subjects were physicians (mean working experience, 6.9 years), either being resident $(n=17)$ or consultant $(n=13)$ in internal medicine $(n=17)$, anesthesiology $(n=8)$, or surgery $(n=5)$. In addition to that 26 nurses with special expertise in emergency and/or intensive care medicine and with a mean working experience of 8.2 years took part in the study.

Reasons to remain in the scanning room were to keep patients in critical conditions under close surveillance and to be able to take appropriate actions immediately (42/56; $75 \%$ ), to calm agitated patients $(9 / 56 ; 16 \%)$, to prevent tubes or cables snagging on the CT bed $(4 / 56 ; 7 \%)$, or to physically restrain patient's body movement $(1 / 56 ; 2 \%)$.

Physicians and nursing staff evaluated the traffic light system quite similar, demonstrated by nearly identical mean scores to question 1 to 4: (physicians/nursing staff) question 1, 4.8/4.8; question 2, 2.2/2.2; question 3, 4.8/4.9; and question 4, 4.6/4.6, respectively (for all, $\mathrm{p}>0.05$ ). Only as to question number 5 assessing knowledge on radiation protection slight differences were evident (2.8/2.6).

With a focus on non-radiological medical staff's years of working experience analysis of the questionnaire revealed that all groups judged the system positively. This was underlined by a mean score of 4.8 (question number 1; $\bullet$ Fig. 2) and the fact that $82 \%$ of study participants "completely agreed" that the stickers were reasonable (score 5 ). There was no significant difference between the groups with different years of working experience $(p=0.473)$. In contrast to that, answers to question number 2 were less uniform ( $\bullet$ Fig. 3), although again no statistically significant difference between the groups was visible $(\mathrm{p}=0.875)$. The mean score was 2.2, and almost two-third of non-radiological medical staff stated that they "completely or partly disagreed that the green stickers are not compatible with patient care". Five of $56(9 \%)$ non-radiological medical professionals were of the opinion that adequate patient supervision is in part impeded by the position of the green stickers.

The groups showed high agreement regarding question number 3 ( $\bullet$ Fig. 4). Almost all (95\%) non-radiological medical professionals at least partly approved the statement that they would strive to stand in the green stickers during the scan, resulting in a mean score of 4.8. Again, no considerable difference between the groups was substantiated $(\mathrm{p}=0.697)$.

Except for 1 non-radiological medical professional, all entrants indicated that the colored stickers improved their feeling of personal radiation safety and reduced uncertainty ( $\bullet$ Fig.5). Although there was an overall agreement to this statement, pointed out by a mean score of 4.6 , groups statistically differed $(p=0.028)$. A strong negative correlation was demonstrated between groups 1 and $3(\rho=-0.567 ; p<0.05)$ and between groups 2 and $3(\rho=-0.53 ; p<0.05)$ and to a lesser degree between groups 1 and $4(\rho=-0.463 ; p<0.05)$ and between groups 2 and $4(\rho=-0.435 ; p<0.05)$, respectively, suggesting that the traffic light system particularly reassured subjects with little working experience.

As underlined by question number 5 overall knowledge on radiation protection was poor (mean score 2.7 ) with $26 / 56$ (46\%) of non-radiological medical professionals admitting that they had no (or only little) idea where their own radiation exposure would be the lowest. Both, between the groups with various working experience as well as within the same group, clear differences were obvious ( Fig. 6 ), pointed out by a p-value of 0.046 . In addition to that, a positive correlation was seen in answers of groups 1 and 3 ( $\rho=0.573 ; p<0.05$ ), implying that more working experience might correlate with improved knowledge of radiation protection.

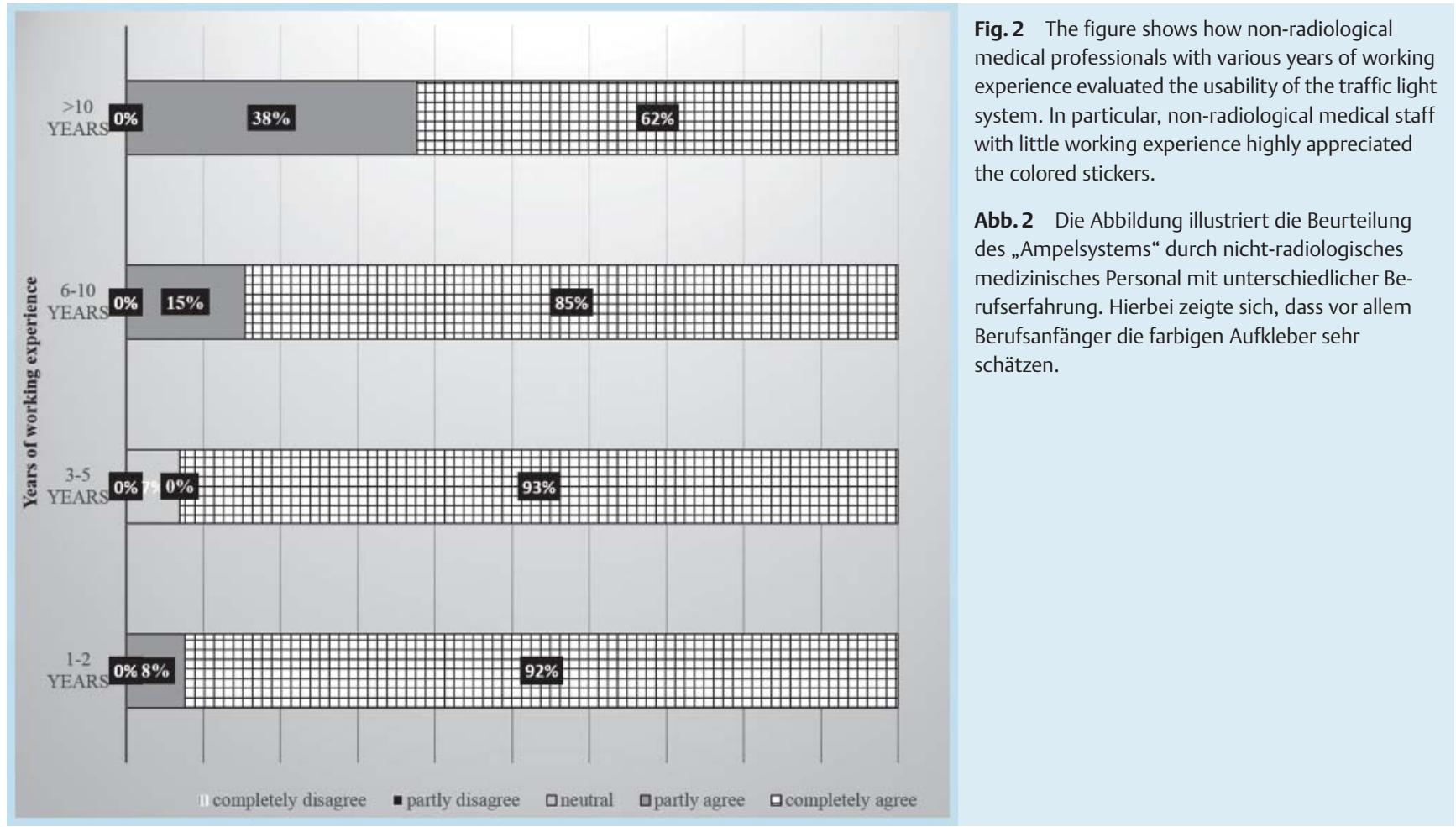




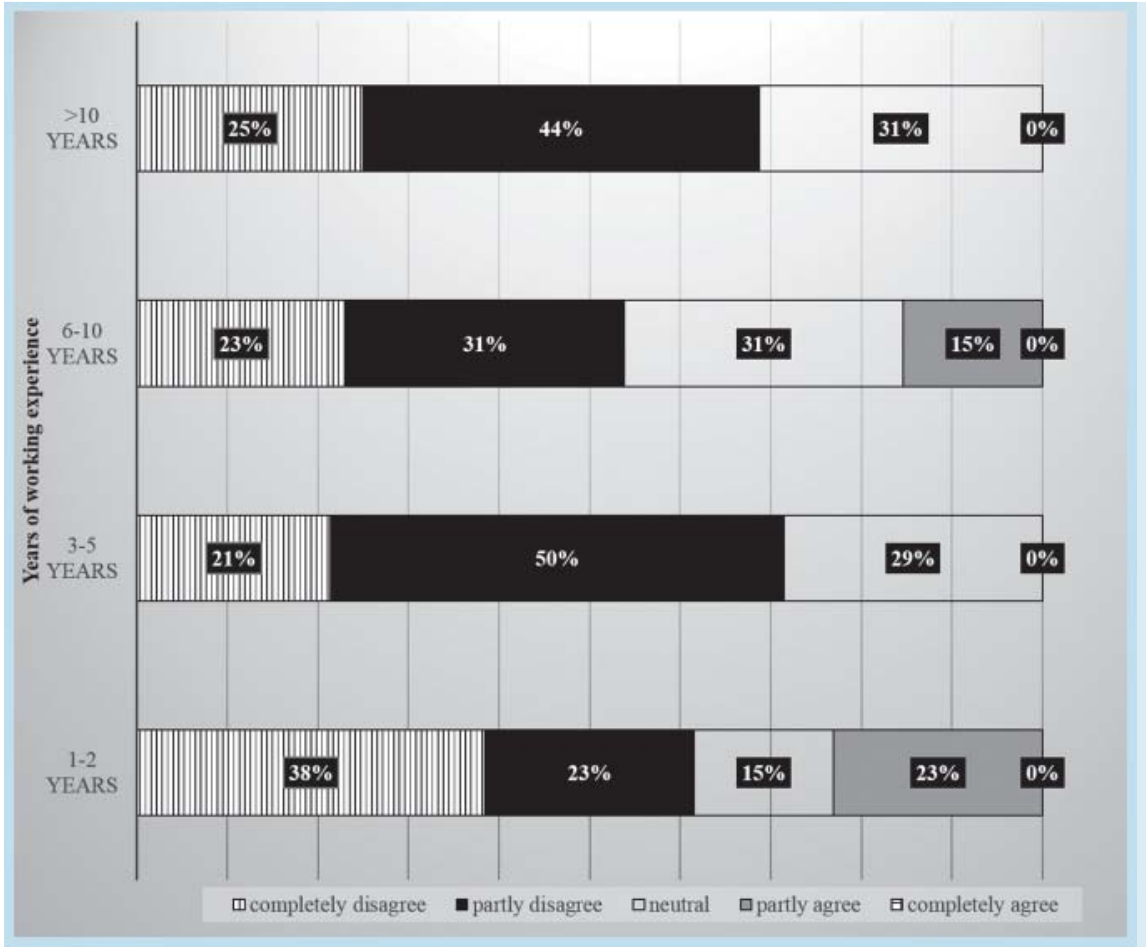

Fig. 3 Summary of responses to question number 2 investigating compatibility of the green colored stickers with patient care. As can be drawn from the figure evaluation was unequal not only between the groups with different years of working experience but also within the same group.

Abb. 3 Zusammenfassung der Antworten zu Frage Nummer 2, die die Vereinbarkeit der Po-sition der grünen Aufkleber mit der Patientenversorgung untersuchte. Wie man der Abbildung entnehmen kann, herrschte sowohl zwischen als auch innerhalb der Gruppen mit unterschiedlicher Berufserfahrung eine deutliche Heterogenität der Antworten.

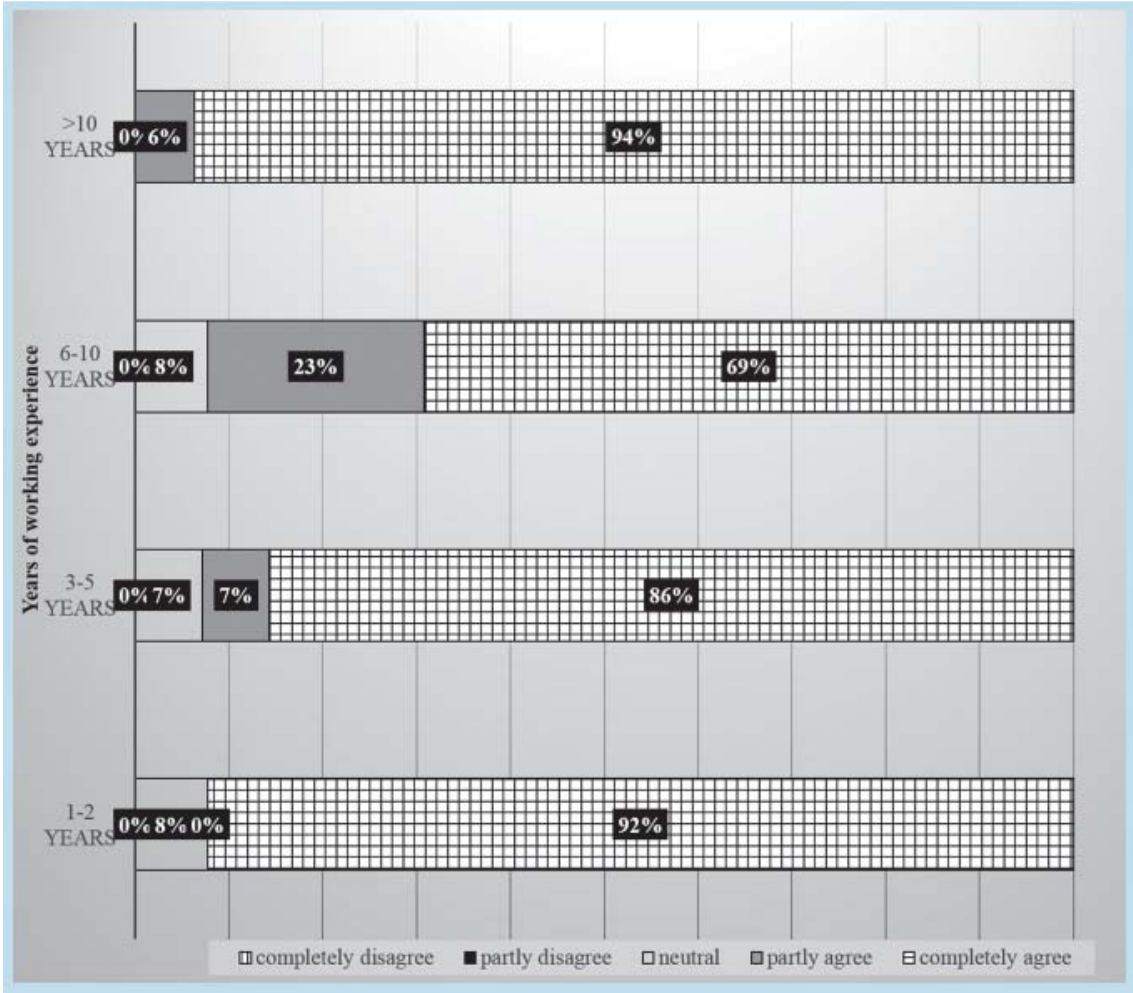

Fig. 4 The figure illustrates whether non-radiological medical professionals would try to stay in the colored stickers during the scan. Irrespective of the years of working experience most of the non-radiological medical staff strives to follow the traffic light system.

Abb. 4 Die Abbildung gibt die Bemühungen von nicht-radiologischem medizinischen Personal wieder, während der Untersuchung die farbigen Aufkleber zu beachten. Es zeigte sich, dass die meisten Befragten unabhängig von den Jahren der Berufserfahrung versuchten, dem „Ampelsystem“ zu folgen.

\section{Discussion}

$\nabla$

With the growing number of computed tomography (CT) scans performed, not only the patients' but also the medical staff's radiation exposure increased [14-16]. Although only limited data on the occupational exposure of non-physician medical professionals is available, indicating that their exposure is less than among physicians [17], there is evidence that even small but re- petitive exposure may lead to a significant increase in the risk of radiation-induced cancer $[2,3,14,18]$. Because of that, occupational radiation protection for all medical professionals is of paramount importance [7]. In addition to tried and true principles of justification, optimization, and limitation, which reduces both patients' and medical professionals' dose [9], protective tools should always be worn if ionizing radiation is applied. 


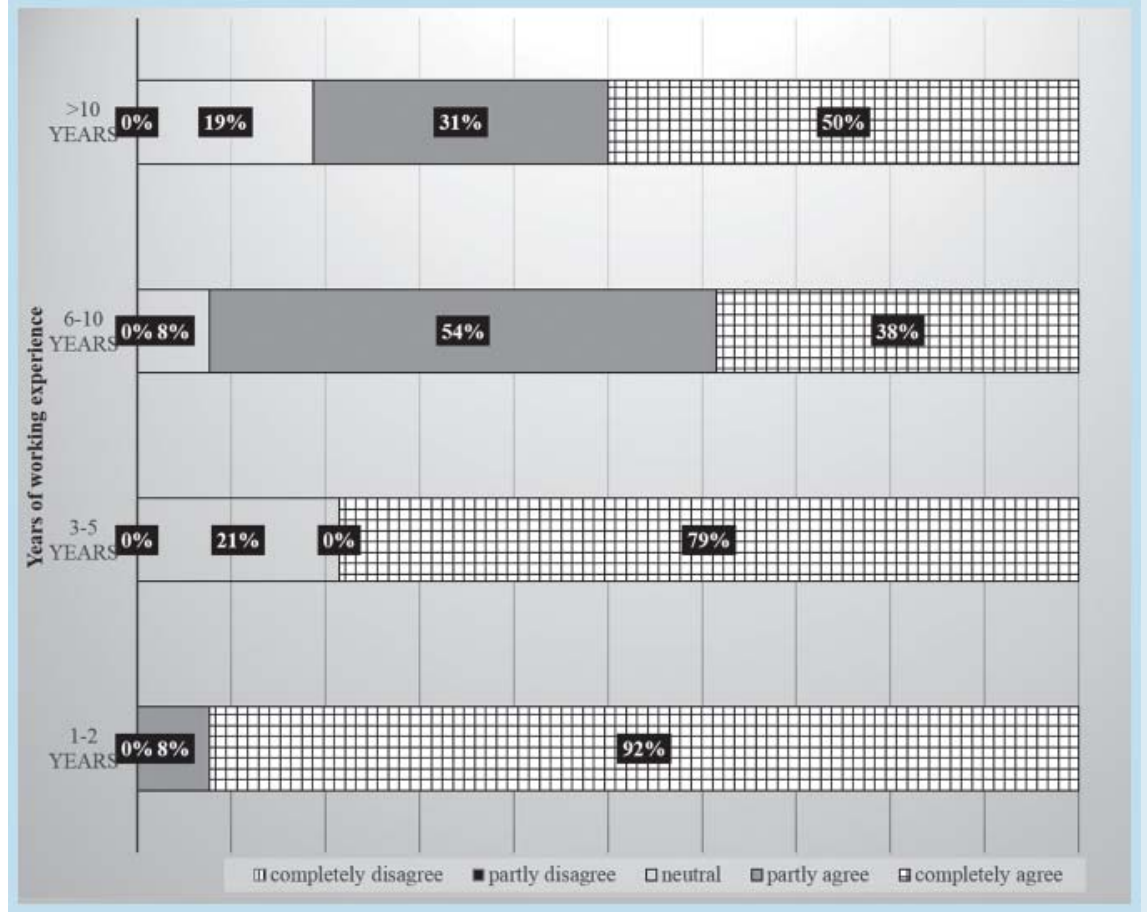

Fig. 5 Summary of answers to the question if the traffic light system improved the non-radiological medical professionals' feeling of personal security. At this, especially entrants felt safer since the colored stickers were mounted on the floor, while benefits were evaluated less remarkably by non-radiological medical staff with $6-10$ years of working experience.

Abb.5 Zusammenstellung der Antworten auf die Frage, ob das „Ampelsystem“ bei dem nicht-radiologischen medizinischen Personal das Gefühl der persönlichen Sicherheit erhöhte. Insbesondere Berufsanfänger fühlten sich durch die Aufkleber sicherer, während Befragte mit 6 - 10 Jahren Berufserfahrung eine weniger deutliche Verbesserung angaben.

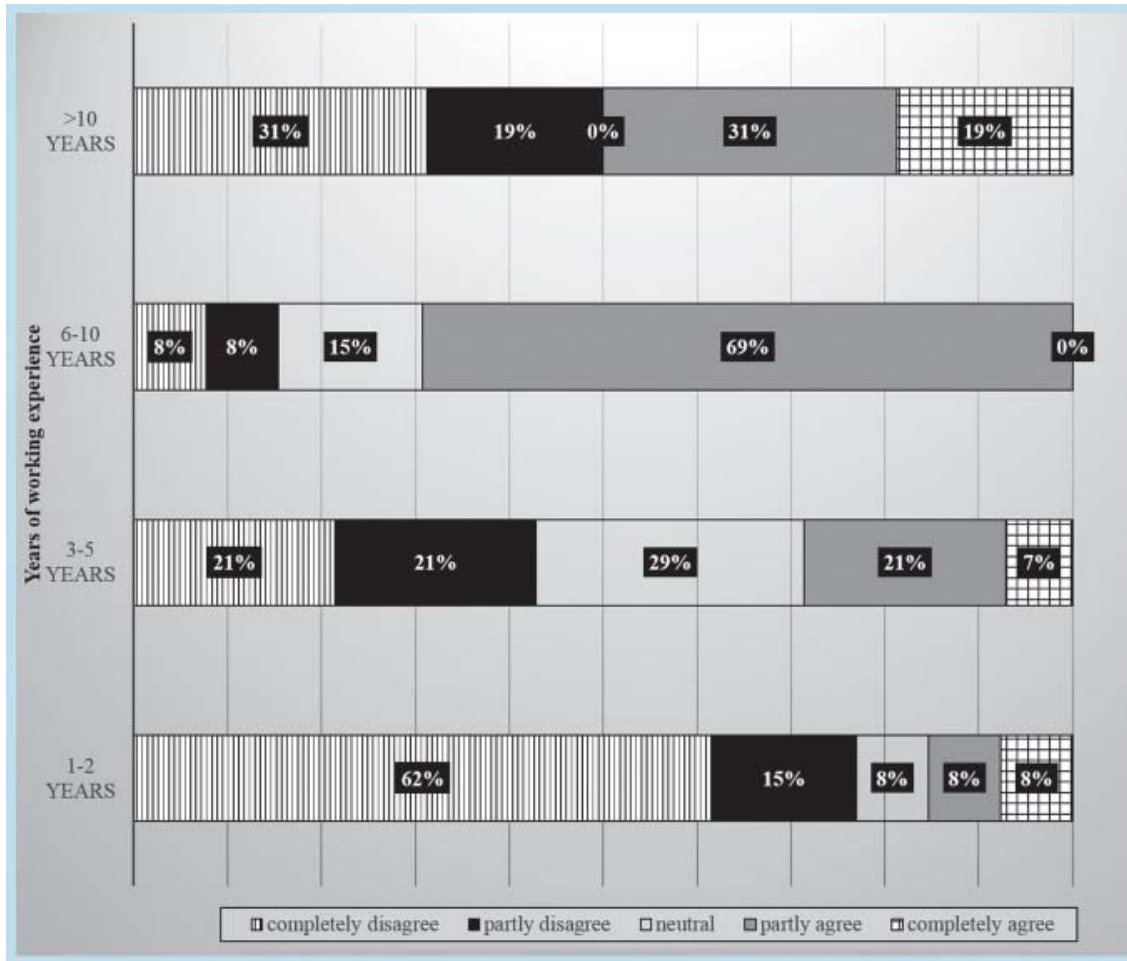

Fig. 6 Assessment of knowledge on radiation safety is depicted in the figure. As can be seen, overall knowledge of radiation exposure was poor with significant differences between groups. In particular, non-radiological medical staff with little working experience previously misjudged their radiation exposure within the scanning room.

Abb. 6 Die Abbildung zeigt, dass das Strahlenschutzwissen der Befragten insgesamt gering war, wobei sich deutliche Unterschiede zwischen den Gruppen fanden. Insbesondere Berufsanfänger schätzten die eigene Strahlenexposition im Untersuchungsraum falsch ein.

Irrespective of the protection equipment positioning within the room in relation to the X-ray beam and to the patient significantly impacts staff's radiation exposure with scattered radiation emanating from the patient in all directions being the main determinant for occupational exposure [7]. However, several studies have documented a lack of knowledge and awareness of radiation exposure and possible protection among medical professionals regardless of their field of expertise $[14,19]$. This is stressed by the observation of a recent study that $85 \%$ of a trau- ma team's members did not wear a lead apron in the trauma bay [20].

As we encountered high uncertainty of our non-radiological medical staff concerning their best position in the CT room during a scan, we decided to tag areas with different radiation exposure adjacent to the CT gantry. We therefore performed phantom measurements and defined positions with the lowest (green), intermediate (orange), and the highest (red) possible dose rate and placed colored stickers on the floor corresponding to a traffic 
light system. Similar to Mori et al. [5] who investigated qualitative and quantitative factors related to radiation exposure to radiologists, highest dose rate was evidenced in the corner between the CT bed and the CT scanner gantry and on the opposite side of the gantry, while lowest radiation exposure was measured at the lateral part of the gantry. The purpose of the orange stickers was to remind the non-radiological medical staff of the inverse square law that already one or two steps removed from the X-ray beam and the gantry significantly reduces their radiation exposure.

Without any doubt, the best radiation protection always is to stay outside the CT room during the scan. We therefore wanted to hear about non-radiological medical professionals' rationale to remain in the scanning room, which revealed similar reasons as described in literature. However, in our study predominantly consisting of emergency and intensive care patients, supervision and surveillance of patients was the most frequent reason, while others specified monitoring of contrast media extravasation as main rationale [5].

In medical professionals, there is a tendency to underestimate radiation exposure and potential harm from imaging tests [14]. Apparently, our colored stickers on the floor improved non-radiological medical staff's radiation awareness as indicated by answers to question number 1 and 3, showing that the traffic light system was highly appreciated and motivated non-radiological medical professionals to stay in the green stickers during the scan. However, about one third of the non-radiological medical staff mentioned that the position of the green stickers might be prejudicial to patient care because patient's face cannot be directly observed from this position, which is regarded the major disadvantage of the stickers. Nevertheless, most of the non-radiological medical professionals agreed that they nevertheless would try to follow the stickers.

Many studies pointed out that knowledge on radiation exposure and protection is clearly lacking in medical professionals $[7,14$, 21 - 23], particularly among medical staff involved in X-ray imaging procedures outside the radiology department [7]. This finding is supported by Zhou et al. [19] and Arslanoglu et al. [24], who detected that the majority of medical professionals were not able to state the radiation dose of various radiological imaging procedures. In agreement with this, state of knowledge on radiation protection was poor in both our physicians and nursing staff with only a slight lead of the physicians, although teaching of radiation protection is usually more elaborated in medical school [22].

Our study was the first to demonstrate that in particular entrants misjudged areas of lowest and highest radiation exposure when compared to non-radiological medical staff with more working experience. However, even in those, who have been accompanying patients for several years, distinct unawareness regarding radiation dose existed. Consequently, our traffic light stickers improved the non-radiological medical professionals' sense of personal security and reduced their uncertainty. Irrespective of this, our data underpins the necessity to improve medical professionals' training and education in radiation exposure and protection as already mentioned by others $[21-23,25]$. At this, recommendations serve to provide more robust education in medical physics and radiation safety in medical school and during residency as well as to introduce regular, mandatory in-service training for technologists and physicians on radiation safety [21, 22]. At the same time, such trainings should aim to overcome the incompliance and negligence towards radiation protection present among some professionals [1].
Our study has some limitations that need to be addressed: (1) it is a single-center study with a rather small sample size in total and particularly within the different groups, which might confine representativeness. (2) Results are based on non-radiological medical professionals' subjective evaluation and therefore personal habits might have influenced answers. (3) Our measurements were performed with a phantom and a single CT protocol, but both a patient's body weight and the X-ray dose to the patient significantly impact level of scatter [7], which are not considered in our study set-up. However, although dose values would change with different set-ups the relation of the green, orange, and red stickers would stay the same.

In conclusion, our study demonstrated that a traffic light system indicating lowest, intermediate, and highest possible radiation exposure in the CT room was highly appreciated by non-radiological medical professionals. The system increased radiation awareness, improved feeling of personal safety, and reduced uncertainty, particularly of medical staff with little working experience. Given clear knowledge gaps concerning radiation protection such a system can be a reasonable component of the endeavor to reduce occupational radiation exposure, although without any doubt, the best radiation protection is to stay outside the CT room during the scan. Therefore, the first step in personal radiation protection should be to scrutinize whether patient supervision requires remaining inside the $\mathrm{CT}$ room.

\section{Clinical relevance:}

- Non-radiological medical staff needed to accompany a patient throughout a CT scan, is often unsure where to stand best to receive lowest possible radiation dose.

- A traffic light system helps to improve feeling of personal security by indicating areas with different radiation exposure.

- Such a traffic light system is much appreciated and increases radiation awareness.

- Especially in entry-level employees, knowledge of radiation protection is poor.

\section{References}

1 Friberg EG, Widmark $A$ et al. Level of compliance with the radiation protection regulation-a survey among Norwegian hospitals and X-ray institutes. Radiat Prot Dosimetry 2011; 147: 223-226

2 Mettler FA, Bhargavan M, Faulkner K et al. Radiologic and nuclear medicine studies in the United States and worldwide: frequency, radiation dose, and comparison with other radiation sources-1950-2007. Radiology 2009; 253: 520-531

3 Hart D, Hillier MC, Wall BF. National reference doses for common radiographic, fluoroscopic and dental X-ray examinations in the UK. Br J Radiol 2009; 82: 1 - 12

4 Larson DB, Johnson LW, Schnell BM et al. National trends in CT use in the emergency department: 1995-2007. Radiology 2011; 258: 164-173

5 Mori $\mathrm{H}$, Koshida $\mathrm{K}$, Ishigamori $\mathrm{O}$ et al. Investigation of qualitative and quantitative factors related to radiological exposure to nursing staff during computed tomography examinations. Health Phys 2014; 107: $\mathrm{S} 202-\mathrm{S} 210$

6 Durán A, Hian SK, Miller DL et al. Recommendations for occupational radiation protection in interventional cardiology. Catheter Cardiovasc Interv Off J Soc Card Angiogr Interv 2013; 82: 29-42

7 Le Heron J, Padovani R, Smith I et al. Radiation protection of medical staff. Eur J Radiol 2010; 76: 20-23

8 ICRP Publication 105. Radiation protection in medicine. Ann. ICRP 2007; 37: 1-63 
9 Dauer LT. Exposed medical staff: challenges, available tools, and opportunities for improvement. Health Phys 2014; 106: 217-224

10 Ross AM, Segal J, Borenstein $D$ et al. Prevalence of spinal disc disease among interventional cardiologists. Am J Cardiol 1997; 79: 68 - 70

11 International Atomic Energy Agency. Radiation Protection and Safety of Radiation Sources: International Basic Safety Standards-Interim Edition, IAEA Safety Standards Series GSR Part 3 (Interim). IAEA; 2011

12 Mundigl S. Modernisation and consolidation of the European radiation protection legislation: the new EURATOM basic safety standards Directive. Radiat Prot Dosimetry 2014; DOI: 10.1093/rpd/ncu285

13 Vañó E, Cosset JM, Rehani MM. Radiological protection in medicine: work of ICRP Committee 3. Ann ICRP 2012; 41: 24-31

14 Sadigh G, Khan R, Kassin MT et al. Radiation safety knowledge and perceptions among residents: a potential improvement opportunity for graduate medical education in the United States. Acad Radiol 2014; 21: 869-878

15 Miller DL, Vañó E, Bartal G et al. Occupational radiation protection in interventional radiology: a joint guideline of the Cardiovascular and Interventional Radiology Society of Europe and the Society of Interventional Radiology. J Vasc Interv Radiol JVIR 2010; 21: 607-615

16 Chida K, Kaga Y, Haga Y et al. Occupational dose in interventional radiology procedures. Am J Roentgenol 2013; 200: 138 -141

17 Teeuwisse WM, Geleijns J, Broerse JJ et al. Patient and staff dose during CT guided biopsy, drainage and coagulation. Br J Radiol 2001; 74: $720-726$
18 Berrington de González A, Darby S. Risk of cancer from diagnostic X-rays: estimates for the UK and 14 other countries. Lancet 2004; 363: $345-351$

19 Zhou GZ, Wong DD, Nguyen LK et al. Student and intern awareness of ionising radiation exposure from common diagnostic imaging procedures. J Med Imaging Radiat Oncol 2010; 54: 17-23

20 Hassan M, Patil A, Channel J et al. Do we glow? Evaluation of trauma team work habits and radiation exposure. J Trauma Acute Care Surg 2012; 73: 605-611

21 Sheyn DD, Racadio JM, Ying J et al. Efficacy of a radiation safety education initiative in reducing radiation exposure in the pediatric IR suite. Pediatr Radiol 2008; 38: 669-674

22 Ramanathan S, Ryan J. Radiation awareness among radiology residents, technologists, fellows and staff: where do we stand? Insights Imaging 2015; 6: 133-139

23 Uri IF. Lack of radiation awareness among referrers: implications and possible solutions. Int J Clin Pract 2012; 66: 574-581

24 Arslanoğlu A, Bilgin S, Kubal Z et al. Doctors' and intern doctors' knowledge about patients' ionizing radiation exposure doses during common radiological examinations. Diagn Interv Radiol Ank Turk 2007; 13: $53-55$

25 European Society of Radiology (ESR). White paper on radiation protection by the European Society of Radiology. Insights Imaging 2011; 2: 357-362 